Strike-Parallel and Strike-Normal Coordinate System Around Geometrically Complicated Rupture TracesUse by NGA-West2 and Further Improvements

Open-File Report 2015-1028 



\section{Strike-Parallel and Strike-Normal Coordinate System Around Geometrically Complicated Rupture Traces- Use by NGA-West2 and Further Improvements}

By Paul Spudich and Brian Chiou

Open-File Report 2015-1028

U.S. Department of the Interior

U.S. Geological Survey 


\section{U.S. Department of the Interior \\ SALLY JEWELL, Secretary}

\section{U.S. Geological Survey \\ Suzette M. Kimball, Acting Director}

U.S. Geological Survey, Reston, Virginia: 2015

For more information on the USGS—-the Federal source for science about the Earth,

its natural and living resources, natural hazards, and the environment-visit

http://www.usgs.gov or call 1-888-ASK-USGS (1-888-275-8747)

For an overview of USGS information products, including maps, imagery, and publications, visit http://www.usgs.gov/pubprod

To order this and other USGS information products, visit http://store.usgs.gov

Any use of trade, firm, or product names is for descriptive purposes only and does not imply endorsement by the U.S. Government.

Although this information product, for the most part, is in the public domain, it also may contain copyrighted materials as noted in the text. Permission to reproduce copyrighted items must be secured from the copyright owner.

Suggested citation:

Spudich, Paul and Chiou, Brian, 2015, Strike-parallel and strike-normal coordinate system around geometrically complicated rupture traces-Use by NGA-West2 and further improvements: U.S. Geological Survey Open-File Report 2015-1028, 20 p., http://dx.doi.org/10.3133/ofr20151028.

ISSN 2331-1258 (online) 


\section{Contents}

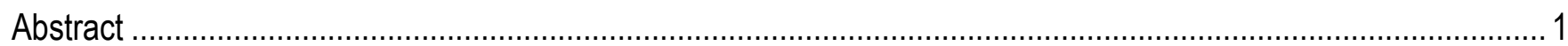

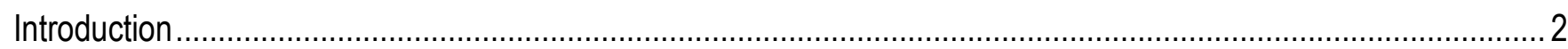

Generalized Coordinate System for a Single Rupture Trace ……….............................................................. 3

Generalized Strike-Normal Coordinate T ................................................................................................ 4

Interpretation in Terms of Subtended Angles....................................................................................

Generalized Strike-Parallel Coordinate U ......................................................................................... 5

Generalized Coordinate System for Multiple Rupture Traces ............................................................................. 5

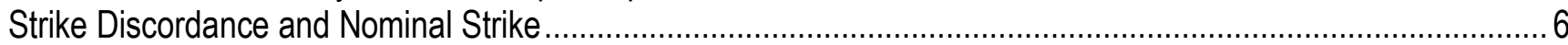

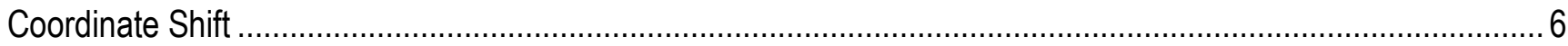

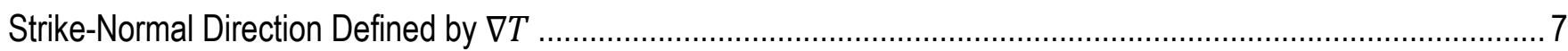

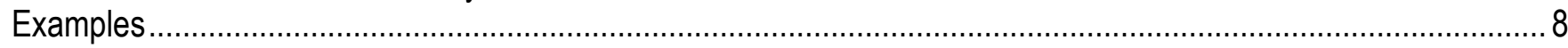

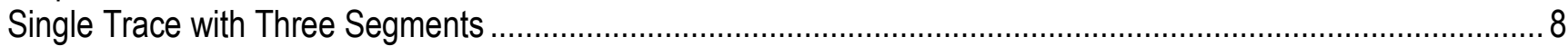

Single Trace with Nine Segments_the 1999 Chi-Chi, Taiwan, Earthquake ................................................... 8

Two Discordant Traces-the 1995 Kobe, Japan, Earthquake......................................................................... 9

Four Discordant Traces-the 2010 El Mayor Cucapah, Mexico, Earthquake ...................................................... 9

Two Overlapping Traces—the 1971 San Fernando, California, Earthquake ......................................................

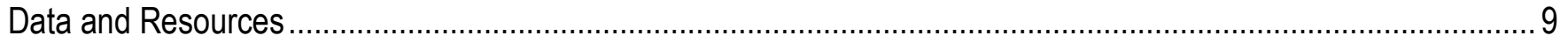

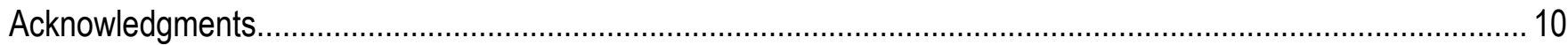

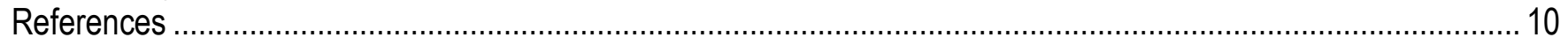

\section{Figures}

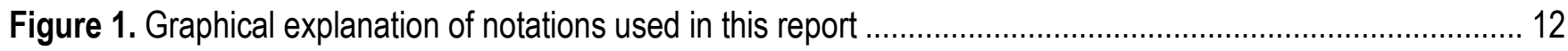

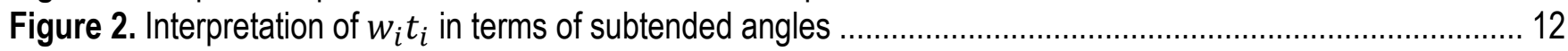

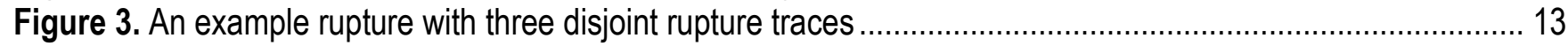

Figure 4. Contour maps of generalized coordinates for a three-segment rupture trace ……............................... 14

Figure 5. Map showing the vector field of GC2's $\nabla T$ for the three-segment test case described in figure 4.......... 15

Figure 6. Contour maps of generalized coordinates for sites located around the rupture trace of the

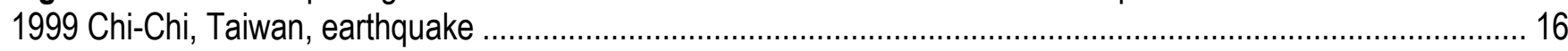

Figure 7. Contour maps of generalized coordinates for sites located around the rupture of the 1995 Kobe,

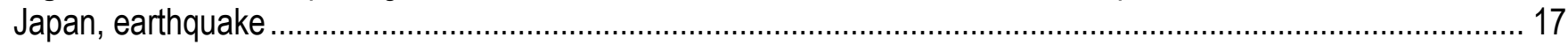

Figure 8. Contour and gradient maps of generalized coordinates for sites located around the rupture of the 2010 El Mayor Cucapah, Mexico, earthquake.

Figure 9. Contour and gradient maps of generalized coordinates for sites located around the rupture of the 1971 San Fernando, California, earthquake 
This page left intentionally blank 


\title{
Strike-Parallel and Strike-Normal Coordinate System Around Geometrically Complicated Rupture Traces- Use by NGA-West2 and Further Improvements
}

\author{
By Paul Spudich¹ and Brian Chiou²
}

\begin{abstract}
We present a two-dimensional system of generalized coordinates for use with geometrically complex fault ruptures that are neither straight nor continuous. The coordinates are a generalization of the conventional strike-normal and strike-parallel coordinates of a single straight fault. The presented conventions and formulations are applicable to a single curved trace, as well as multiple traces representing the rupture of branching faults or noncontiguous faults. An early application of our generalized system is in the second round of the Next Generation of Ground-Motion Attenuation Model project for the Western United States (NGA-West2), where they were used in the characterization of the hanging-wall effects. We further improve the NGA-West2 strike-parallel formulation for multiple rupture traces with a more intuitive definition of the nominal strike direction. We also derive an analytical expression for the gradient of the generalized strike-normal coordinate. The direction of this gradient may be used as the strike-normal direction in the study of polarization effects on ground motions.
\end{abstract}

\footnotetext{
${ }^{1}$ U.S. Geological Survey.

${ }^{2}$ California Department of Transportation.
} 


\section{Introduction}

The Next Generation of Ground-Motion Attenuation Model project (NGA) is a multidisciplinary research program coordinated by the Lifelines Program of the Pacific Earthquake Engineering Research Center (PEER). The goal of the NGA project is to develop new ground-motion prediction equations (GMPE), through comprehensive and collaborative research. In the development of the NGA-West 1 GMPEs (Power and others, 2008) and the companion directivity models (Spudich and Chiou, 2008), it was necessary to define the strike-normal $(T)$ and strike-parallel $(U)$ coordinates of sites located around earthquake ruptures having traces - whose definition is given later in this section - that were neither straight nor continuous (for example, curved en-echelon traces). In three of the NGA-West1 GMPEs the strike-normal coordinate was used to model the strike-perpendicular variation of hanging-wall effects for sites directly above the rupture plane. In the companion directivity models, both coordinates were used to define the generalized radiation coefficient for a curved rupture. For geometrically complex traces, it is also useful to define a strike-normal direction at arbitrary sites. Spudich and Chiou (2008) developed a generalized coordinate system (GC1) to accomplish these two tasks, but their system produced $U$ coordinates that did not vary smoothly. In addition, their $T$ coordinates were excessively vulnerable to perturbation by short lengths of fault segments at the ends of fault systems. One of the causes of the aforementioned flaws was the reliance of their algorithm on identifying the point on the rupture trace closest to the site (henceforth this point will be called simply the closest point). For a fault that bends along strike, a small change in the site location could yield a large discontinuous change in the location of its closest point.

To fix the abovementioned problems, we formulated a new generalized coordinate system (GC2). The new system was used in the development of the NGA-West2 GMPEs ((Bozorgnia and others, 2014). In this report, we present the conventions and formulations of GC2 and further improve the formulation for $U$ coordinate with a more intuitively defined nominal strike direction. We also derive an analytical expression for the gradient of the generalized $T$ coordinate, whose direction may be used to define the strike-normal direction at arbitrary sites for the study of polarization effects on ground motions.

We will refer to the vertical projection of the top edge of rupture on the ground surface as the rupture trace. The rupture trace coincides with the fault trace, except for the case where an earthquake source on a dipping fault does not rupture all the way to the ground surface. The rupture trace has traditionally been used as the reference line with respect to which we define the locations where groundmotion amplitude is expected to be modified by hanging-wall effects (Abrahamson and Somerville, 1996; Chiou and Youngs, 2008) and directivity effects (Somerville and others, 1997). For this reason, we base the generalized coordinate system on the rupture trace, rather than on the fault trace.

As does common practice, we represent a curved rupture trace by a sequence of contiguous line segments to model the strike variation along the rupture length. The term segment is used in this report in a purely geometric context. Our new formulation is based on averaging coordinates over these segments, weighted by $1 / r^{2}$; a precise definition will be given later. GC2 is as straightforward to calculate as GC1, yet it produces much smoother coordinates and possesses several other useful properties. 
Not every earthquake rupture can be properly represented by a single trace consisting of contiguous segments. Earthquakes that rupture along noncontiguous faults or branching faults are not uncommon. Past examples include the 1995 Kobe, Japan, earthquake (M 6.9), the 1999 Denali, Alaska, earthquake (M 7.9), and the 2010 El Mayor Cucapah, Mexico, earthquake (M 7.2). In addition, the source model in seismic hazard analysis (for example, Field and others, 2013) often includes scenarios of fault-to-fault jumps and fault branching that are deemed plausible on geological and dynamic grounds. With these ruptures being modeled by multiple traces, we propose an extension of the singletrace formulation by which a generalized coordinate system can be established around multiple traces.

The generalized coordinate system is fully defined by the positions of endpoints and interior points of the rupture trace(s), where each interior point signals a change in strike direction. In practice, however, a segment is sometimes further divided, by adding spurious interior points along that segment, to model within-segment variation in slip rate, dip, or rake angle. We formulate GC2 in such a way that it is independent of this type of non-strike-related within-segment subdivision. Furthermore, being defined in a plane on the ground surface, GC2 is completely independent of the locations of the buried parts of the rupture, except that the direction of strike is defined according to the fault dip direction. GC2 is also independent of the process of rupture propagation along the fault plane.

The remainder of this report is structured as follows. First, we present the GC2 formulation for the basic case of a single rupture trace. We then propose an algorithm to allow reusing this formulation for the more complex case of several rupture traces. Next, we derive an analytic expression of the gradient of $T$ that works in both cases. Finally, we present and discuss the generalized coordinates and the $T$ gradients of several example ruptures.

\section{Generalized Coordinate System for a Single Rupture Trace}

In this report, a vector is written in boldface and a hat is added if it is also a unit vector. We represent a point in the easting-northing coordinate system by a vector in standard position (for example, $\boldsymbol{p}_{1}$ ). When necessary, a vector is explicitly written as terminal minus initial points, such as $\boldsymbol{p}_{2}-\boldsymbol{p}_{1}$.

Suppose there are $n$ line segments in a rupture trace, $n \geq 2$. The rupture trace is defined by the positions of its two endpoints $\left\{\boldsymbol{p}_{1}, \boldsymbol{p}_{n+1}\right\}$ and $n-1$ interior points $\left\{\boldsymbol{p}_{2}, \ldots, \boldsymbol{p}_{n}\right\}$ (fig. 1). The order of these points matters; it must be such that $\widehat{\boldsymbol{u}}_{i}=\left(\boldsymbol{p}_{i+1}-\boldsymbol{p}_{i}\right) / l_{i}$ is the unit vector in the strike direction of the $i^{t h}$ segment, where $l_{i}=\left|\boldsymbol{p}_{i+1}-\boldsymbol{p}_{i}\right|$ is the length of the $i^{\text {th }}$ segment. We use the same convention as used in Aki and Richards (1980), where the fault always dips to the right when viewed in its strike direction. The strike-normal unit vector of the $i^{t h}$ segment is defined as $\widehat{\boldsymbol{t}}_{i}=\widehat{\boldsymbol{u}}_{i} \times \hat{\boldsymbol{z}}$, where $\hat{\boldsymbol{z}}$ is the unit vector in the up direction.

With $\boldsymbol{p}_{i}$ serving as the origin, $\hat{\boldsymbol{t}}_{i}$ and $\widehat{\boldsymbol{u}}_{i}$ form a local two-dimensional strike-normal and strikeparallel Cartesian coordinate system that is specific to the $i^{\text {th }}$ segment. The position of an arbitrary site $\boldsymbol{Y}$ in a local system is explicitly written in component form $\left(t_{i}, u_{i}\right)$, for which we use the subscript $i$ to denote the segment number of the local system. 


\section{Generalized Strike-Normal Coordinate T}

The previous generalized system, GC1, assigned weight only to the segment of the closest point. Such weighting scheme is unsatisfactory, as explained in the Introduction. The new generalized coordinate $T$ represents a weighted average of $t_{i}$ over all segments of the rupture trace, weighted in such a way that coordinate $T$ varies smoothly with space and is progressively dominated by the nearest segment as site $\boldsymbol{Y}$ approaches the rupture trace. After experimenting with several alternative schemes, we select the inverse-squared-distance weight,

$$
w_{i}=\int_{0}^{l_{i}} \frac{1}{r^{2}} d u
$$

and define the new generalized coordinate $T$ as

$$
\begin{gathered}
T=W^{-1} \sum_{i=1}^{n} w_{i} t_{i} \\
W=\sum_{i=1}^{n} w_{i} .
\end{gathered}
$$

In equation 1, variable $r$ is the distance from site $\boldsymbol{Y}$ to a general point $\boldsymbol{u}$ on the $i^{\text {th }}$ segment (fig. 1). We also tested schemes using $r^{-1}$ and $r^{-4}$, but $r^{-2}$ had the pleasing property that the $T=0$ contour far from the fault trace followed a line through the endpoints of the trace (see discussions in the next section), and in general its contours were the least distorted at corners and ends of the trace.

An important computational advantage of equation 1 is that it can be evaluated in closed form:

1. For $t_{i} \neq 0$, site $\boldsymbol{Y}$ does not lie on the $i^{\text {th }}$ segment or its extension and

$$
w_{i}=\frac{1}{t_{i}}\left[\tan ^{-1}\left(\frac{l_{i}-u_{i}}{t_{i}}\right)-\tan ^{-1}\left(\frac{-u_{i}}{t_{i}}\right)\right]
$$

Here, the convention $-\frac{\pi}{2}<\tan ^{-1}(\cdot)<\frac{\pi}{2}$ is adhered to.

2. For $t_{i}=0, u_{i}<0$ or $u_{i}>l_{i}$, site $\boldsymbol{Y}$ lies on the extension of the $i^{\text {th }}$ segment and

$$
w_{i}=\frac{1}{u_{i}-l_{i}}-\frac{1}{u_{i}} .
$$

3. For $t_{i}=0$ and $0 \leq u_{i} \leq l_{i}, \boldsymbol{Y}$ lies on the $i^{\text {th }}$ segment and $w_{i}$ is undefined due to singularity in its integrand. In this case, we simply declare $T=0$.

Incidentally, the absolute value of coordinate $T$ is the parameter $R_{X}$, included in the NGA-West2 database (Ancheta and others, 2014).

\section{Interpretation in Terms of Subtended Angles}

There is a useful geometric interpretation of $w_{i} t_{i}$ and $W T$. Referring to equation 4 and figure 2 ,

$$
\begin{gathered}
\tan ^{-1}\left(\frac{l_{i}-u_{i}}{t_{i}}\right)=\phi_{i}^{(l-u)}, \\
\tan ^{-1}\left(\frac{-u_{i}}{t_{i}}\right)=\phi_{i}^{(-u)}, \\
w_{i} t_{i}=\phi_{i}^{(l-u)}-\phi_{i}^{(-u)}=\Delta \phi_{i}=\angle \boldsymbol{p}_{i} \boldsymbol{Y} \boldsymbol{p}_{i+1}, \text { and } \\
W T=\sum_{i} w_{i} t_{i}=\sum_{i} \Delta \phi_{i}=\angle \boldsymbol{p}_{1} \boldsymbol{Y} \boldsymbol{p}_{n+1},
\end{gathered}
$$


The sign of $\Delta \phi_{i}$ is dictated by the sign of $t_{i}$. While the above interpretation does not remove the need to calculate $w_{i}$, it is a helpful check. With equation 7 , it is easy to show that $T$ is invariant to nonstrike-related within-segment subdivision. In addition, equation 8 leads to the useful result that $T=0$ off of the ends of the rupture trace is along the line passing through the two endpoints $\boldsymbol{p}_{1}$ and $\boldsymbol{p}_{n+1}$; see, for example, figure 4.

\section{Generalized Strike-Parallel Coordinate U}

Similar to coordinate $T$, we want the generalized coordinate $U$ to be a weighted average of all $u_{i}$, but with their respective origins shifted to a common origin. We define $U$ as

$$
U=W^{-1} \sum_{i=1}^{n} w_{i}\left(u_{i}+s_{i}\right)
$$

Variable $s_{i}$ represents the amount of shift of $\boldsymbol{p}_{i}$ (origin of the $i^{\text {th }}$ local system) to the common origin. The weight $w_{i}$ in equation 9 is the same weight as that used in the definition of generalized coordinate $T$, with one modification: when $\boldsymbol{Y}$ lies on the $i^{\text {th }}$ segment (in other words, $t_{i}=0$ and $\left.0 \leq u_{i} \leq l_{i}\right), w_{i}$ is undefined and we simply declare $U=u_{i}+s_{i}$.

Although the common origin (where $U=0$ ) may be placed anywhere along the rupture trace, we prefer placing it at the first endpoint $\boldsymbol{p}_{1}$, so that the $U$ coordinate on the rupture trace is positive. Incidentally, when the common origin is placed at the midpoint of the rupture trace, the resulting $U$ is the parameter $R_{Y}$ included in the NGA-West2 database (Ancheta and others, 2014).

The coordinate shift, $s_{i}$, may be measured in several different ways. We prefer measuring it along the rupture trace,

$$
s_{i}=\sum_{k=1}^{i-1} l_{k}
$$

With this definition, the $U$ coordinate is invariant to non-strike-related within-segment subdivision, which is also a property of coordinate $T$. In addition, the $U$ coordinate of $\boldsymbol{p}_{n+1}$ is equal to the length of the rupture trace.

\section{Generalized Coordinate System for Multiple Rupture Traces}

Suppose there are $m$ rupture traces, $m \geq 2$. We want all $m$ traces to contribute to the generalized coordinates. We achieve this by linking the traces to form a single trace so that we can reuse the singletrace formula described earlier. The linking process involves two sequential operations. First, for each member whose strike direction disagrees with the general strike direction of the entire fault system, we reverse the order in which its defining points are specified, essentially turning its strike by $180^{\circ}$. The algorithm to identify discordant members is described in section "Strike Discordance and Nominal Strike." Next, we connect the traces by inserting $m-1$ fictitious traces to fill in the gaps. The inserted traces are fictitious because all are given a zero weight so that they do not contribute to the generalized coordinates.

In addition, to reuse the single-trace formula for strike-parallel coordinate $U$, we also need to specify the common origin and reformulate the coordinate shift to reflect the presence of multiple traces. They are described in section "Coordinate Shift." 


\section{Strike Discordance and Nominal Strike}

In a multi-trace situation, the strike direction of each rupture trace may not agree with the others. Strike discordance, if uncorrected, could lead to an egregious outcome; as an illustration, see the coordinates shown in figure 7 for the Kobe, Japan, earthquake. In the following paragraph, we describe the algorithm we developed to identify discordant members.

First, an east-trending trial vector, $\boldsymbol{a}$, is formed by connecting the two endpoints most distant from each other. Let $\widehat{\boldsymbol{a}}$ be the unit vector in the direction of $\boldsymbol{a}$. Next, we introduce a second subscript $j$ to denote the trace number. We calculate $e_{j}=\left(\boldsymbol{p}_{n+1, j}-\boldsymbol{p}_{1, j}\right) \cdot \widehat{\boldsymbol{a}}$ and sum $e_{j}$ over all traces, $E=$ $\sum_{j=1}^{m} e_{j}$. If $e_{j}$ and $E$ have different signs, the $j^{t h}$ trace is a discordant member and its strike is reversed. Finally, we sum the end-minus-end vectors, for which strike discordance has been corrected,

$$
\boldsymbol{b}=\sum_{j=1}^{m}\left(\boldsymbol{p}_{n+1, j}-\boldsymbol{p}_{1, j}\right)^{*} \text {. }
$$

The $*$ is there to remind us of the correction. The unit vector $\widehat{\boldsymbol{b}}$ is the nominal strike of the multi-trace system.

We use the example system shown on figure 3 to illustrate the aforementioned process: $\boldsymbol{a}=$ $\left(\boldsymbol{p}_{3}-\boldsymbol{p}_{6}\right)=(6.654,3.328) ; \widehat{\boldsymbol{a}}=(0.894,0.448) ; e_{1}=\left(\boldsymbol{p}_{9}-\boldsymbol{p}_{6}\right) \cdot \widehat{\boldsymbol{a}}=2.236 ; e_{2}=\left(\boldsymbol{p}_{2}-\boldsymbol{p}_{1}\right) \cdot \widehat{\boldsymbol{a}}=$ 1.669; $e_{3}=\left(\boldsymbol{p}_{5}-\boldsymbol{p}_{3}\right) \cdot \widehat{\boldsymbol{a}}=-1.999 ; E=e_{1}+e_{2}+e_{3}=1.906$. Because $e_{3}$ has a different sign from $E$, fault member 3 is discordant, and for the purpose of calculating $U$ and $T$, its strike is reversed by rearranging the rupture trace from $\left(\boldsymbol{p}_{3}, \boldsymbol{p}_{4}, \boldsymbol{p}_{5}\right)$ to $\left(\boldsymbol{p}_{5}, \boldsymbol{p}_{4}, \boldsymbol{p}_{3}\right)$. Finally, $\boldsymbol{b}=\left(\boldsymbol{p}_{9}-\boldsymbol{p}_{6}\right)+\left(\boldsymbol{p}_{2}-\boldsymbol{p}_{1}\right)+$ $\left(\boldsymbol{p}_{3}-\boldsymbol{p}_{5}\right)=(5.654,1.895)$ and $\widehat{\boldsymbol{b}}=(0.948,0.318)$. We should note that this fault system is made exceptionally complex for illustration purpose; it is not an earthquake source we expect to see in reality.

\section{Coordinate Shift}

U's origin $\left(\boldsymbol{p}_{\text {origin }}\right)$ is selected from the two endpoints most distant from each other. We choose the one that is on the back end of the nominal strike direction, so that a point on the rupture traces has a positive $U$ coordinate.

We do not reuse equation (10) because the fictitious traces would have introduced extraneous shifts, particularly when rupture traces significantly overlap each other. We revise it to

$$
s_{i, j}=\left(\sum_{k=1}^{i-1} l_{k, j}\right)+\left(\boldsymbol{p}_{1, j}-\boldsymbol{p}_{\text {origin }}\right)^{*} \cdot \widehat{\boldsymbol{b}}
$$

where

$l_{k, j}$ is the length of the $k^{\text {th }}$ segment in the $j^{\text {th }}$ (real) trace,

$\boldsymbol{p}_{1, j}$ is the first endpoint of the $j^{\text {th }}$ trace, and

$\widehat{\boldsymbol{b}}$ is the nominal strike defined earlier.

We prefer equation (12) because $\widehat{\boldsymbol{b}}$ is the direction of the $T=0$ line at far-source distances. We note that the NGA-West 2 project used a different definition of nominal strike for a coordinate shift. Specifically, the project chose $(\operatorname{sign}(E) \widehat{\boldsymbol{a}})$ as the nominal strike direction, thus

$$
s_{i, j}=\left(\sum_{k=1}^{i-1} l_{k, j}\right)+\left(\boldsymbol{p}_{1, j}-\boldsymbol{p}_{\text {origin }}\right)^{*} \cdot(\operatorname{sign}(E) \widehat{\boldsymbol{a}}) .
$$

For clarity, we refer the version using equation 12 as $\mathrm{GC}_{\mathrm{T}}$, and the version using equation 13 as $\mathrm{GC} 2{ }_{\mathrm{N}}$. All of the figures shown in this report are for $\mathrm{GC} 2_{\mathrm{T}}$. 


\section{Strike-Normal Direction Defined by $\nabla T$}

Because the generalized coordinates $U$ and $T$ are not mutually orthogonal, we choose to use the gradient of $T$, which is orthogonal to $T$, to define the strike-normal direction at an arbitrary site. From equation 2 ,

$$
\begin{aligned}
\nabla T & =\sum_{i=1}^{n} \nabla\left(W^{-1} w_{i} t_{i}\right) \\
& =\sum_{i=1}^{n}\left(\partial_{N}\left(W^{-1}\right) w_{i} t_{i}+W^{-1} \partial_{N}\left(w_{i} t_{i}\right)\right) \widehat{N}+\left(\partial_{E}\left(W^{-1}\right) w_{i} t_{i}+W^{-1} \partial_{E}\left(w_{i} t_{i}\right)\right) \widehat{\boldsymbol{E}}
\end{aligned}
$$

$\widehat{\boldsymbol{N}}$ and $\widehat{\boldsymbol{E}}$ are the unit vectors in the north and east direction, respectively. Symbol $\partial_{N}($.$) denotes$ the partial derivative with respect to northing, and $\partial_{E}($.$) to easting. All derivatives are analytically$ derived; no numerical differentiation needs to be taken. The algebraic expression for each of the partial derivatives in equation 14 is given below.

Partial derivatives of $W^{-1}$ are

$$
\begin{gathered}
\partial_{N} W^{-1}=-W^{-2} \sum_{i=1}^{n} t_{i}^{-1}\left(\partial_{N}\left(w_{i} t_{i}\right)-w_{i}\left(\widehat{\boldsymbol{N}} \cdot \hat{\boldsymbol{t}}_{i}\right)\right) \text { and } \\
\partial_{E} W^{-1}=-W^{-2} \sum_{i=1}^{n} t_{i}^{-1}\left(\partial_{E}\left(w_{i} t_{i}\right)-w_{i}\left(\widehat{\boldsymbol{E}} \cdot \hat{\boldsymbol{t}}_{i}\right)\right) .
\end{gathered}
$$

Partial derivatives of $w_{i} t_{i}$ are

$$
\begin{gathered}
\partial_{N}\left(w_{i} t_{i}\right)=\left(\beta_{i}^{(N)}, \gamma_{i}^{(N)}\right) \cdot\left(\alpha_{i}^{(1)}, \alpha_{i}^{(2)}\right) \text { and } \\
\partial_{E}\left(w_{i} t_{i}\right)=\left(\beta_{i}^{(E)}, \gamma_{i}^{(E)}\right) \cdot\left(\alpha_{i}^{(1)}, \alpha_{i}^{(2)}\right),
\end{gathered}
$$

where

$$
\begin{gathered}
\gamma_{i}^{(N)}=t_{i}^{-1}\left(\widehat{\boldsymbol{N}} \cdot \widehat{\boldsymbol{u}}_{i}\right)-u_{i} t_{i}^{-2}\left(\widehat{\boldsymbol{N}} \cdot \hat{\boldsymbol{t}}_{i}\right), \\
\gamma_{i}^{(E)}=t_{i}^{-1}\left(\widehat{\boldsymbol{E}} \cdot \widehat{\boldsymbol{u}}_{i}\right)-u_{i} t_{i}^{-2}\left(\widehat{\boldsymbol{E}} \cdot \hat{\boldsymbol{t}}_{i}\right), \\
\beta_{i}^{(N)}=t_{i}^{-2}\left(u_{i}-l_{i}\right)\left(\widehat{\boldsymbol{N}} \cdot \hat{\boldsymbol{t}}_{i}\right)-t_{i}^{-1}\left(\widehat{\boldsymbol{N}} \cdot \widehat{\boldsymbol{u}}_{i}\right), \\
\beta_{i}^{(E)}=t_{i}^{-2}\left(u_{i}-l_{i}\right)\left(\widehat{\boldsymbol{E}} \cdot \hat{\boldsymbol{t}}_{i}\right)-t_{i}^{-1}\left(\widehat{\boldsymbol{E}} \cdot \widehat{\boldsymbol{u}}_{i}\right), \\
\alpha_{i}^{(1)}=\left[1+\left(\frac{l_{i}-u_{i}}{t_{i}}\right)^{2}\right]^{-1}, \text { and } \\
\alpha_{i}^{(2)}=\left[1+\left(\frac{u_{i}}{t_{i}}\right)^{2}\right]^{-1} .
\end{gathered}
$$

Although the expression for $\nabla T$ is derived for a single-trace configuration, it is also applicable to a multi-trace configuration after the traces are linked together to form a single trace using the procedure described earlier.

In the NGA-West2 project, an ad hoc definition of local strike-parallel direction was used in rotating the two horizontal components of the acceleration time series to the strike-normal and strike-parallel components (Ancheta and others, 2014). This ad hoc direction was defined as the average strike direction over a $20 \mathrm{~km}$ (or less) stretch of fault segment beginning at the closest point on the fault and extending towards the epicenter. However, we prefer the direction of $\nabla T$ as the strike-normal direction for rotating recorded acceleration time series because of its consistency with the generalized $T$ coordinate, and its independence from the closest point. As shown in the examples described below, the direction of $\nabla T$ is consistent with our intuition and it varies smoothly even in the case of a geometrically complex rupture. 


\section{Examples}

The same conventions and GC2 formulations described above can be used for all ruptures, even if they are simple in geometry or have a single fault plane. However, for the examples described below, we purposely choose ruptures that are more complex than those commonly used, in order to better contrast GC1 and GC2 and to illustrate a few possible limitations of GC2. We expect GC1 and GC2 to produce similar results when the geometry is not as complex

\section{Single Trace with Three Segments}

We begin with a modestly complex three-segment rupture to compare the results of GC1 and GC2. In figure 4, the $T$ and $U$ coordinates of GC1 are shown on the left two panels and GC2 on the right two panels. There are several distinct differences between GC1 and GC2. First, off of the ends of the rupture trace, the $T$ contours of GC1 are parallel to the end segment; this is because in $\mathrm{GC} 1, T$ is defined as the strike-normal coordinate $\left(t_{i}\right)$ of the closest segment, which is the end segment. In contrast to $\mathrm{GC} 1$, the $T$ contours of GC2 are subparallel to the line passing through the two endpoints (dashed line in figure $4 B$ ), and in fact, the $T=0$ contour coincides with the end-to-end line, as was shown earlier. In passing, it is a coincidence that the second segment is parallel to the end-to-end line. Secondly, within the ends of the rupture trace, the spacing between the $T$ contours of GC2 is shorter on the concave side of the trace than on the convex side. Contrastingly, the spacing of GC1 is almost identical on both sides of the trace. Thirdly, on the concave side of the rupture trace, the $U$ contours of GC1 converge, while the contours on the convex side diverge. This convergence-divergence behavior is much less severe for the $U$ coordinate of GC2, making it a better measure of the along-strike distance.

Figure 5 illustrates the appropriateness of using the direction of the $T$ gradient as the strikenormal direction. For sites off of the ends of the rupture trace, the direction of $\nabla T$ is nearly perpendicular to the end-to-end line $(T=0)$. For sites within the ends and on the convex side of the trace, the direction of $\nabla T$ is roughly perpendicular to one of the three segments. For sites on the concave side of the trace, the direction of $\nabla T$ is influenced by all three segments. Overall, the directional field of $\nabla T$ varies smoothly around the rupture trace

\section{Single Trace with Nine Segments—the 1999 Chi-Chi, Taiwan, Earthquake}

The M 7.6 Chi-Chi earthquake is an example of a geometrically complex rupture on a reverse fault. In the NGA-West 2 project, its rupture trace is modeled by nine contiguous line segments (thick solid line in fig. 6). Its complexity is shown by the $338^{\circ}$ of total absolute change in strike direction, with the largest change of $60^{\circ}$ occurring between the two northernmost segments.

Contours of $T$ and $U$ around the rupture trace are shown in figure 6. They exhibit general characteristics that are similar to those of the three-segment trace described earlier. A flaw of the GC1 system is exemplified by the glitches in its $T$ coordinate in the second quadrant of figure $6 \mathrm{~A}$. This flaw is due to the large discontinuous change in the location of the closest point associated with the two northernmost segments. Another flaw of the GC1 system is shown by the irregular spacing of $U$ contours, making GC1's $U$ less tenable as a measure of along-strike distance for sites within the ends of a complex rupture trace 


\section{Two Discordant Traces—-the 1995 Kobe, Japan, Earthquake}

The finite-fault model of the M 6.9 Kobe earthquake (Wald, 1996) includes two rupture planes whose strikes are in opposite direction. To demonstrate the egregious consequences of strike discordance, the coordinates calculated using the original strike of the northeast trending, southwest dipping, Nojima Fault segment are shown in figures $7 A, C$; the coordinates calculated using our proposed procedure are shown in figures $7 B, D$. Without imposing the strike reversal, the $T=0$ and the $U=0$ contours cross the rupture traces and the results are simply unreasonable as coordinates.

The results shown in figure $7 B$ suggest a potential complication associated with the use of our $T$ coordinate to characterize the hanging-wall effects when there is strike discordance among the multiple traces. Specifically, due to the strike reversal, the positive sign of the $T$ coordinate is no longer indicative of being on the hanging wall of the Nojima Fault. If a modeler wants to model the hangingwall effects of the Nojima Fault, then an additional hanging-wall indicator must be created and used for that purpose

\section{Four Discordant Traces-the 2010 El Mayor Cucapah, Mexico, Earthquake}

The finite fault model of the M 7.2 El Mayor Cucapah earthquake (Wei and others, 2011) is shown in figure 8. It is similar to the Kobe earthquake in that it includes two long rupture traces in opposite strike direction. It also includes two much shorter traces, one located in between the two longer traces and the other at the northern end. The strikes of the two shorter traces deviate considerably from the general strike direction of the two longer traces. Despite the additional complexity introduced by the two shorter traces, the overall patterns of the $T$ and $U$ coordinates are not very different from those of the Kobe earthquake. The two shorter traces create some local perturbations to GC2 coordinates (figs. $8 B, D)$, but nothing prominent on a global scale.

\section{Two Overlapping Traces-the 1971 San Fernando, California, Earthquake}

The finite fault model of the M 6.6 San Fernando earthquake consists of two concordant rupture planes on the San Fernando and the Sierra Madre Faults (Heaton, 1982). The two rupture traces, separated by about $5 \mathrm{~km}$, are subparallel and of roughly equal length (fig. 9). The $T=0$ contour bends to connect these two traces. The area bracketed by the two rupture traces is reasonably divided by the $T=0$ contour into a positive subarea on the hanging-wall side of the San Fernando Fault and a negative subarea on the footwall side of the Sierra Madre Fault. Despite the $5 \mathrm{~km}$ separation between the two traces, the absolute $T$ value inside the bracketed area is less than $1 \mathrm{~km}$.

\section{Data and Resources}

The three-segment fault trace used in this report came from Pacific Earthquake Engineering Research Center's project on Verification of Probabilistic Seismic Hazard Analysis Computer Programs (Christina Denissen Hale, Pacific Earthquake Engineering Research Center, written commun., 2014). The finite-fault data of the other four example earthquakes came from the NGA-West 2 database (http://peer.berkeley.edu/ngawest2/databases/). GC1 and GC2 were implemented in the software platforms R and MATLAB. All of the graphics were prepared using the basic graphics functions of R. 


\section{Acknowledgments}

We thank D. Boore, B. Aagaard, and especially A. Baltay of the USGS for their prompt and helpful review comments. M. Garcia-Feuss prepared an early typeset version of the mathematics. We thank C. Donlin, L. Rogers, S. Wahlstrom, K. Jacques, and M. Diggles of the USGS Publishing Service Centers for going above and beyond to prepare this work for publication quickly. This work was initiated as part of the NGA-West 2 project of the Pacific Earthquake Engineering Research Center and was partially supported by the California Earthquake Authority, California Department of Transportation, and the Pacific Gas \& Electric Company. Any opinions, findings, and conclusions or recommendations expressed in this material are those of the authors and do not necessarily reflect those of the above mentioned agencies.

\section{References}

Abrahamson, N., and Somerville, P.G., 1996, Effects of the hanging wall and footwall on ground motions recorded during the Northridge earthquake: Bulletin of the Seismological Society of America, v. 86, no. 1B, p. S93-S99.

Aki, K., and Richards, P., 1980, Quantitative Seismology, Theory and Methods, Volume I: New York, Freeman, $557 \mathrm{p}$.

Ancheta, T., Darragh, R., Stewart, J., Seyhan, E., Silva, W., Chiou, B., Wooddell, K., Graves, R., Kottke, A., Boore, D., Kishida, T., and Donahue, J., 2014, NGA-West2 database: Earthquake Spectra, v. 30, p. 989-1005.

Bozorgnia, Y., Abrahamson, N.A., Atik, L.A., Ancheta, T.D., Atkinson, G.M., Baker, J., Baltay, A., Boore, D., Campbell, K., Chiou, B., Darragh, R.D., Day, S., Donahue, J., Graves, R., Gregor, N., Hanks, T., Idriss, I.M., Kamai, R., Kishida, T., Kottke, A., Mahin, S., Rezaeian, S., Rowshandel, B., Seyhan, E., Shahi, S., Shantz, T., Silva, W., Spudich, P., Stewart, J., Watson-Lamprey, J., Wooddell, K., and Youngs, R., 2014, NGA-West2 research project: Earthquake Spectra, v. 30, p. 973-987.

Chiou, B., and Youngs, R., 2008, NGA model for the average horizontal component of peak ground motion and response spectra: Pacific Earthquake Engineering Research Center, University of California, Berkeley, Calif., PEER Report 2008/09, 94 pg.

Field, E.H., Biasi, G.P., Bird, P., Dawson, T.E., Felzer, K.R., Jackson, D.D., Johnson, K.M., Jordan, T.H., Madden, C., Michael, A.J., Milner, K.R., Page, M.T., Parsons, T., Powers, P.M., Shaw, B.E., Thatcher, W.R., Weldon, R.J., II, and Zeng, Y., 2013, Uniform California earthquake rupture forecast, version 3 (UCERF3) - The time-independent model: U.S. Geological Survey Open-File Report 20131165, 97 p., California Geological Survey Special Report 228, and Southern California Earthquake Center Publication 1792, http://pubs.usgs.gov/of/2013/1165/.

Heaton, T., 1982, The 1971 San Fernando earthquake; A double event?: Bulletin of the Seismological Society of America, v. 72, p. $1311-1341$.

Power, M., Chiou, B., Abrahamson, N., Bozorgnia, Y., Shantz, T., and Roblee, C., 2008, An overview of the NGA Project: Earthquake Spectra, v. 24, p. 3-21.

Somerville, P., Smith, N., Graves, R., and Abrahamson, N., 1997, Modification of empirical strong ground motion attenuation relations to include the amplitude and duration effects of rupture directivity: Seismological Research Letters, v. 68, p. 199-222.

Spudich, P., and Chiou, B., 2008, Directivity in NGA earthquake ground motions; analysis using isochrone theory: Earthquake Spectra, v. 24, p. 279-298. 
Wald, J., 1996, Slip history of the 1995 Kobe, Japan, earthquake determined from strong motion, teleseismic, and geodetic data: Journal of Physics of the Earth, v. 44, no. 5, p. 489-503.

Wei, S., Fielding, E., Leprince, S., Sladen, A., Avouac, J., Helmberger, D., Hauksson, E., Chu, R., Simons, M., Hudnut, K., Herring, T., and Briggs, R., 2011, Superficial simplicity of the $2010 \mathrm{El}$ Mayor-Cucapah earthquake of Baja California in Mexico: Nature Geoscience, v. 4, p. 615-618. 


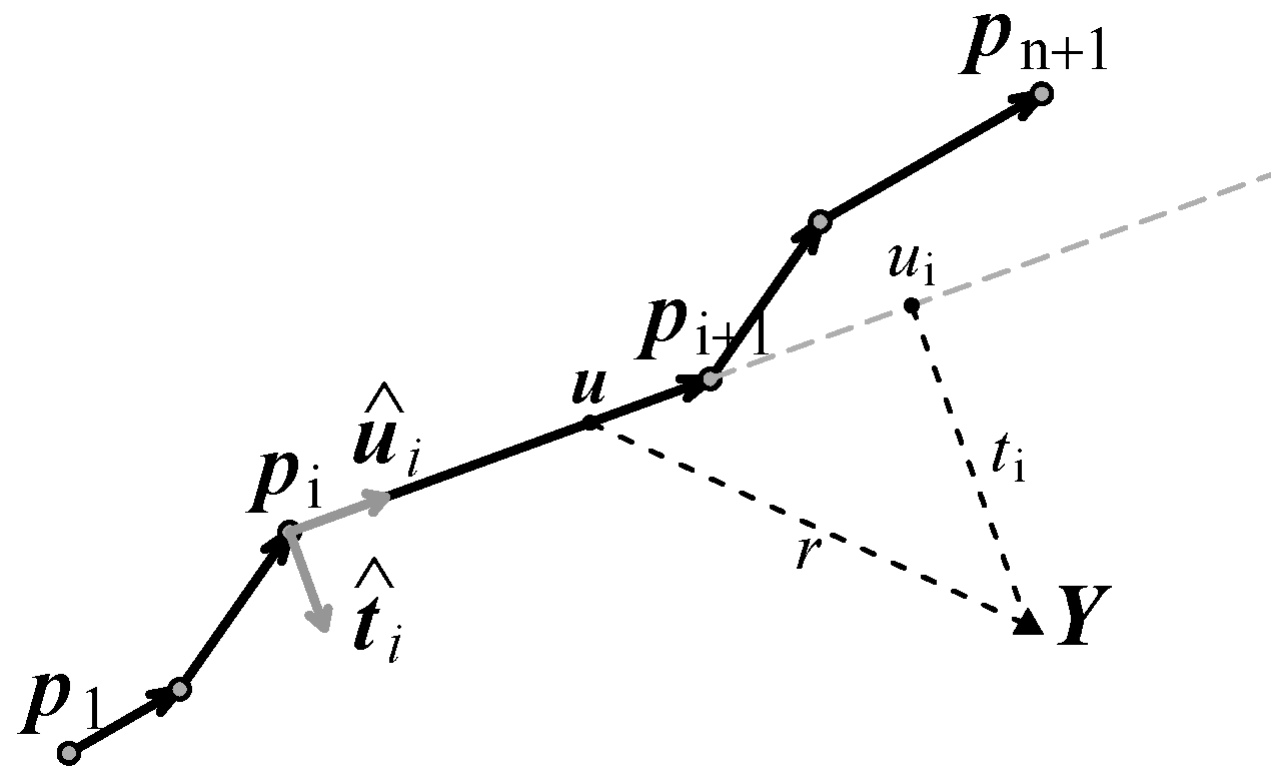

Figure 1. Graphical explanation of notations used in this report.

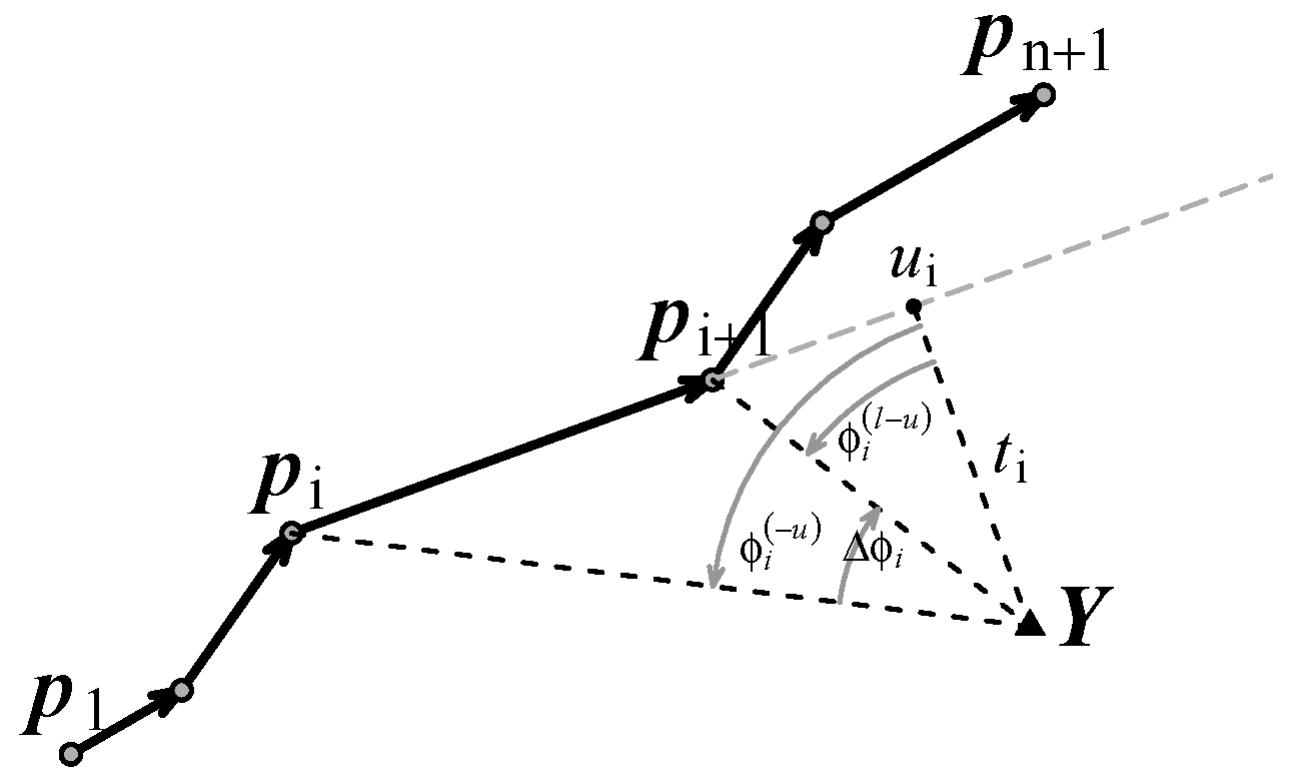

Figure 2. Interpretation of $w_{i} t_{i}$ in terms of subtended angles. 


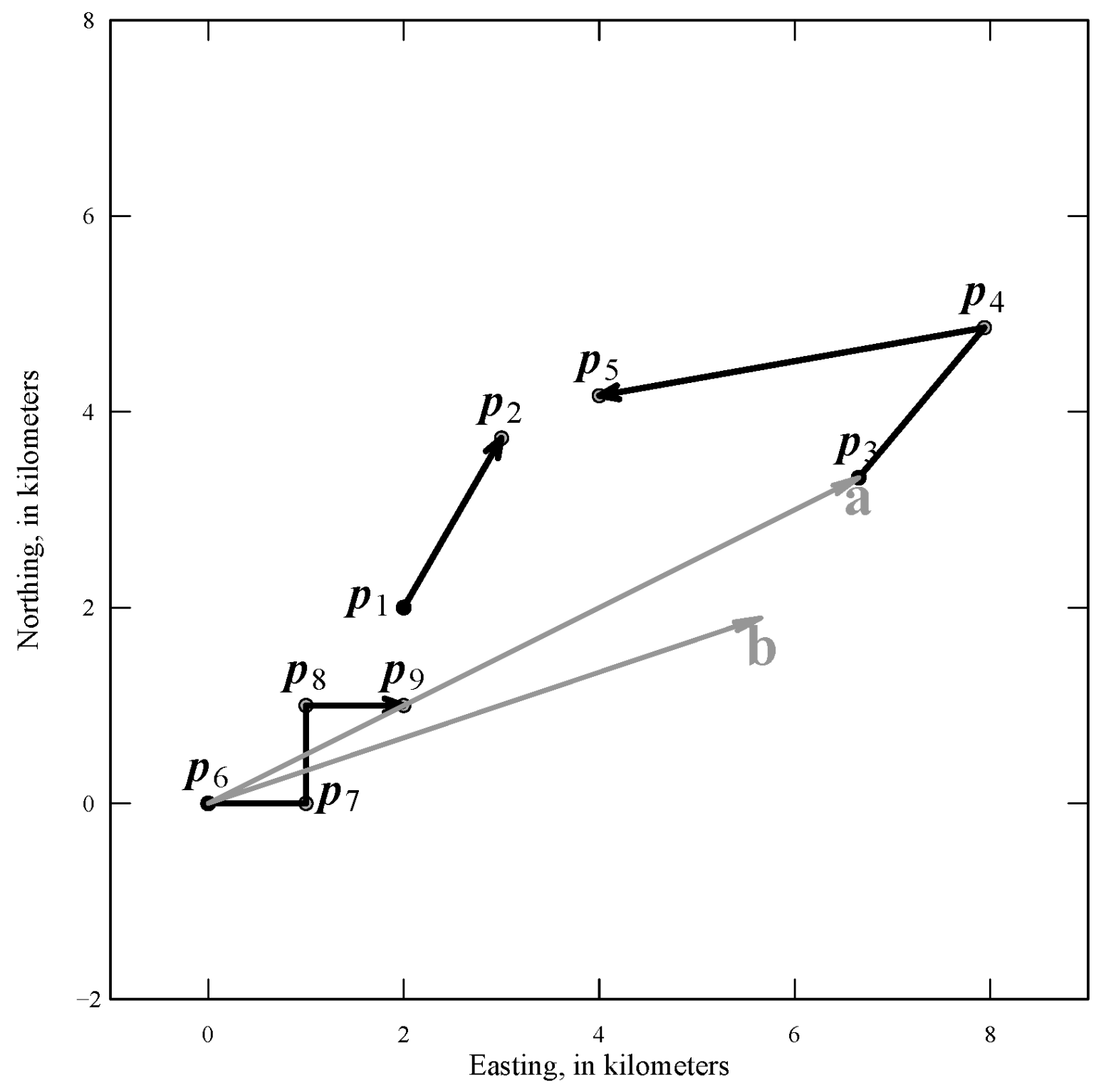

Figure 3. An example rupture with three disjoint rupture traces. The solid black circle denotes the beginning endpoint and the arrow denotes the terminal endpoint of a rupture trace. The easting-northing coordinates of the defining points are: $\boldsymbol{p}_{1}=(2,2) ; \boldsymbol{p}_{2}=(3.000,3.732) ; \boldsymbol{p}_{3}=(6.654,3.328) ; \boldsymbol{p}_{4}=(7.939,4.860) ; \boldsymbol{p}_{5}=$ $(4.000,4.165) ; \boldsymbol{p}_{6}=(0,0) ; \boldsymbol{p}_{7}=(1,0) ; \boldsymbol{p}_{8}=(1,1) ; \boldsymbol{p}_{9}=(2,1)$. 

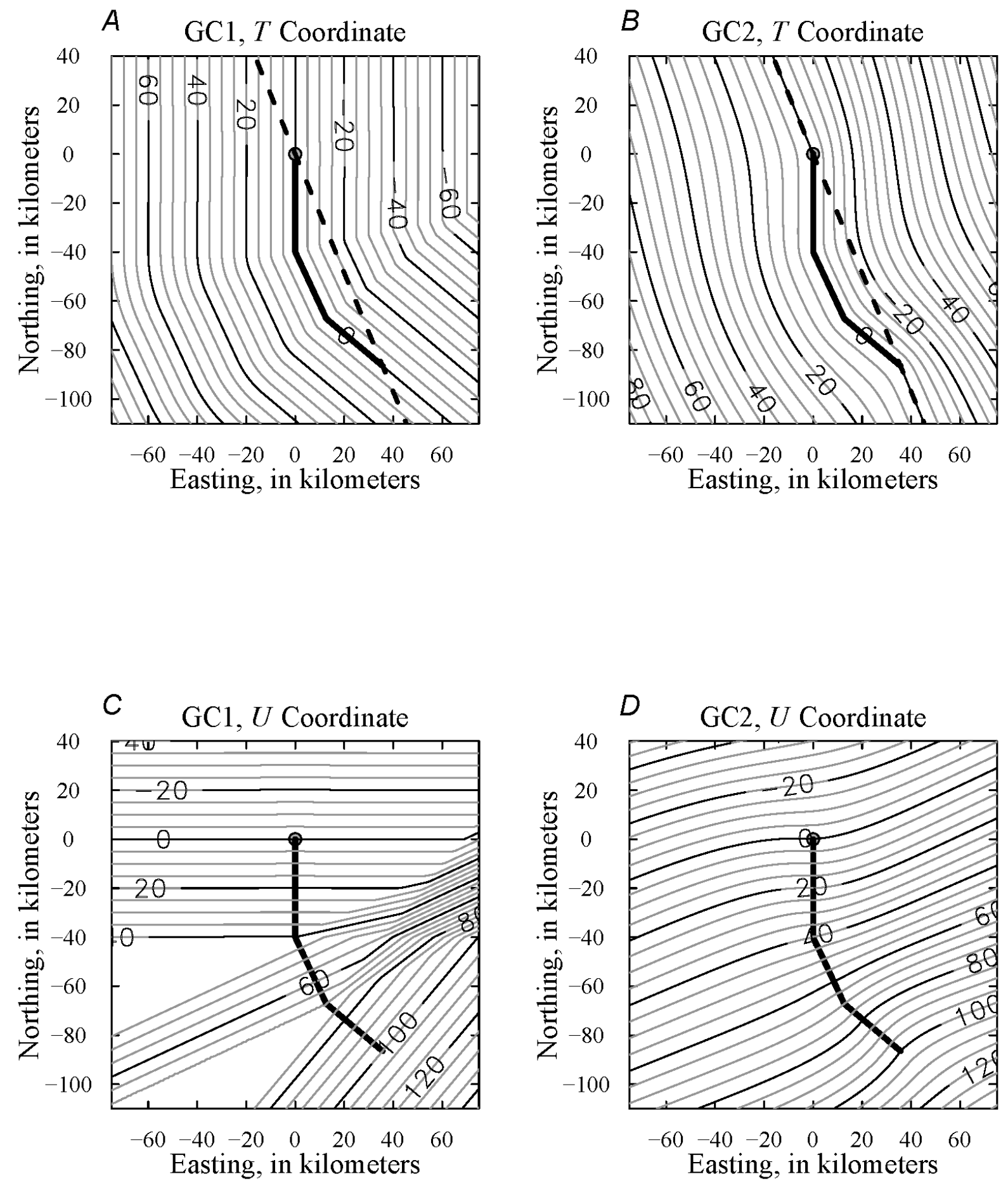

Figure 4. Contour maps of generalized coordinates for a three-segment rupture trace. A, T coordinate of GC1; $B, T$ coordinate of GC2; $C, U$ coordinate of GC1; $D, \cup$ Coordinate of GC2. The rupture trace, shown as the thick solid line, includes one $40-\mathrm{km}$ south-trending segment and two $30-\mathrm{km}$ segments trending $155^{\circ}$ and $130^{\circ}$, respectively. The easting-northing coordinates of the four trace-defining points are: $(0,0),(0,-40),(12.68,-67.19)$, and (35.66, -86.47). Gray solid point, common origin of $U$; thick dashed line, the line passing through the two endpoints, which is also in the direction of the nominal strike $\widehat{\boldsymbol{b}}$. 


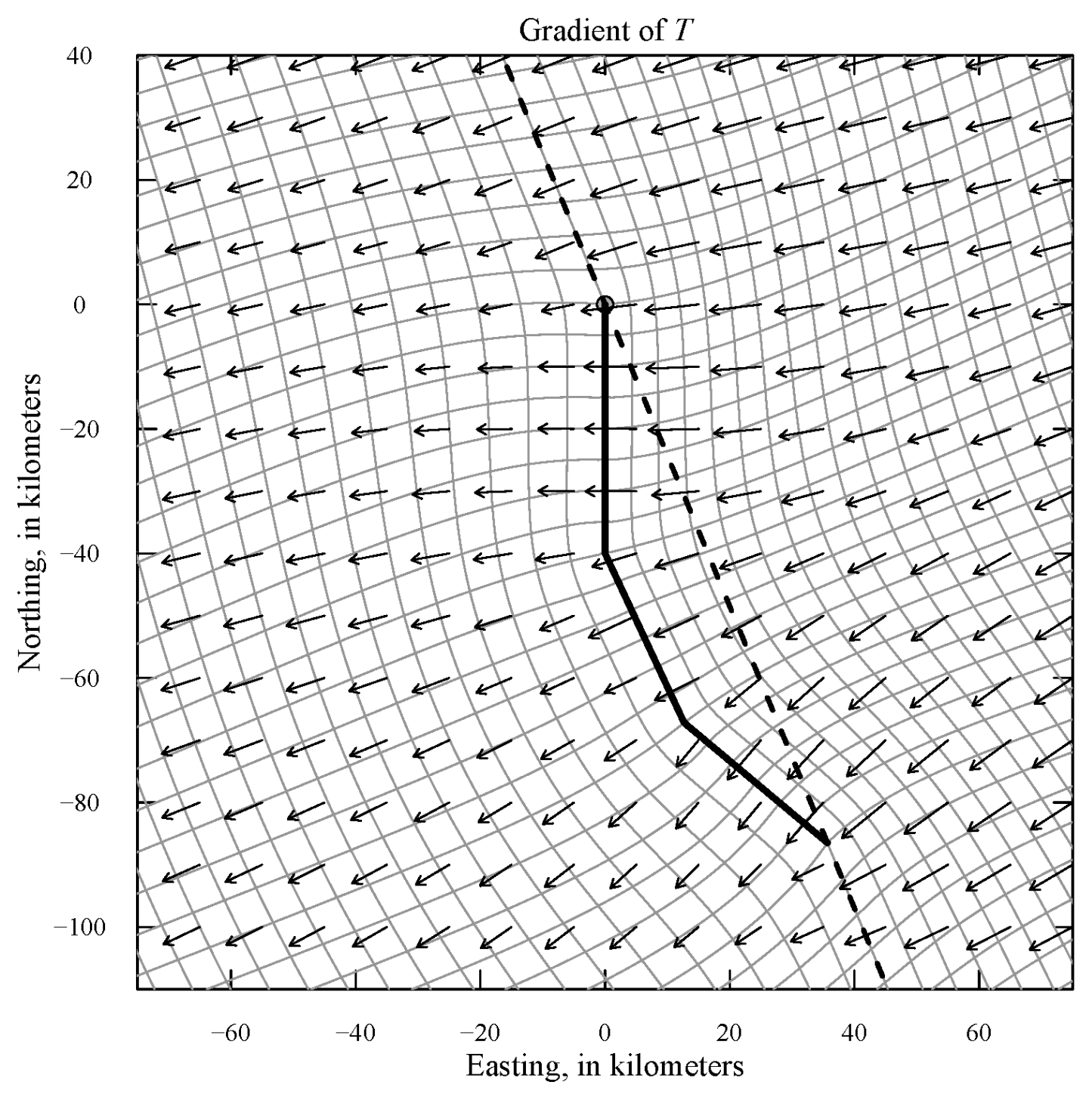

Figure 5. Map showing the vector field of GC2's $\nabla T$ for the three-segment test case described in figure 4 . The amplitude of $\nabla T$ is proportional to the length of arrow. Gray lines, the GC2 contours shown in figure 4; thick solid line, rupture trace; gray solid point, common origin of $U$; thick dashed line, the line passing through the two endpoints, which is also in the direction of the nominal strike $\widehat{\boldsymbol{b}}$. 

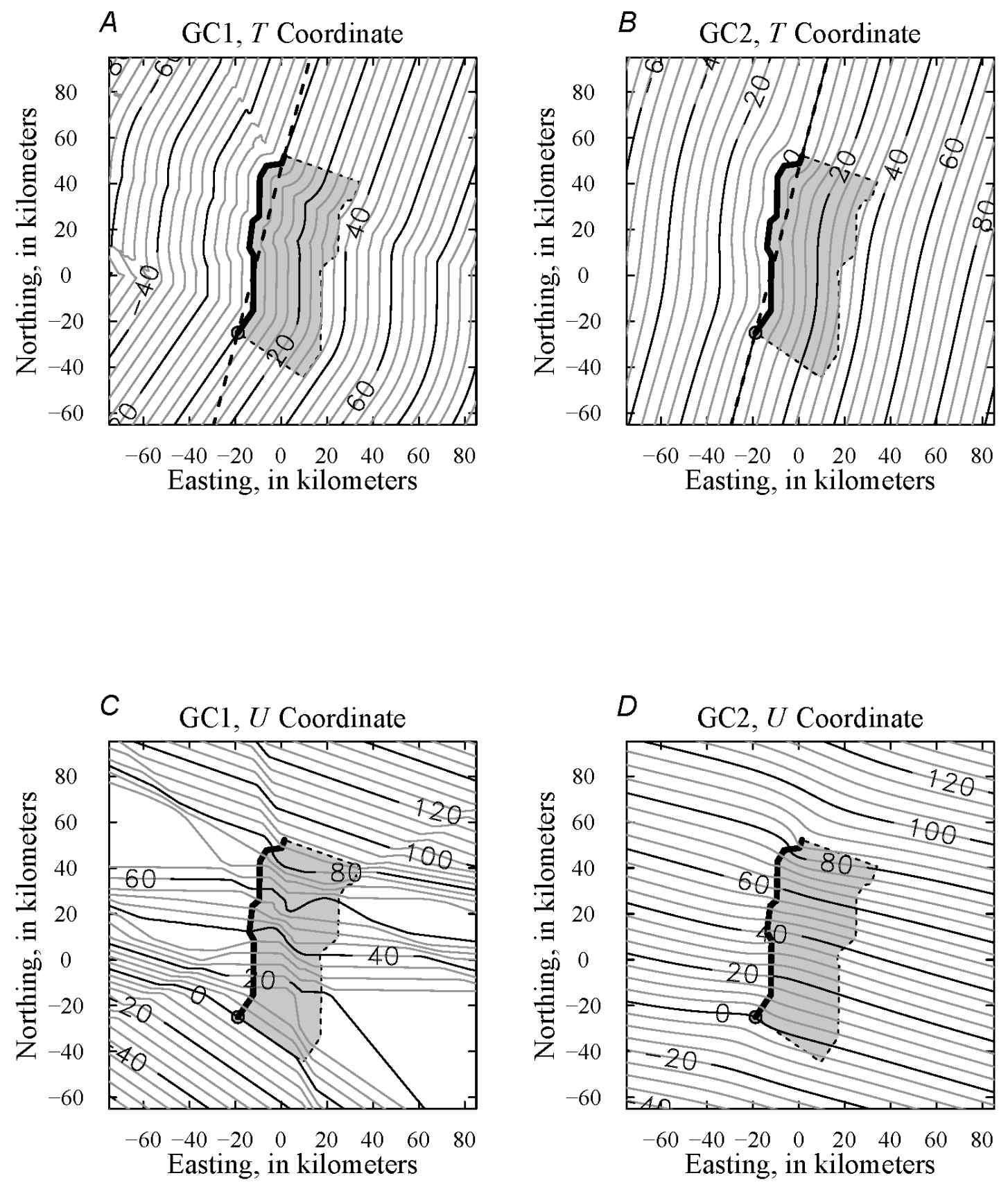

Figure 6. Contour maps of generalized coordinates for sites located around the rupture trace of the $1999 \mathrm{Chi}-\mathrm{Chi}$, Taiwan, earthquake. $A, T$ coordinate of $\mathrm{GC} 1 ; B, T$ coordinate of $\mathrm{GC} 2$; $C, U$ coordinate of $\mathrm{GC1}$; D, $U$ coordinate of GC2. Thick solid line, the rupture trace of the Chi-Chi earthquake; gray solid point, common origin of $U$; shaded area, buried part of the rupture; thick dashed line, the line passing through the two endpoints, which is also in the direction of the nominal strike $\widehat{\boldsymbol{b}}$. 

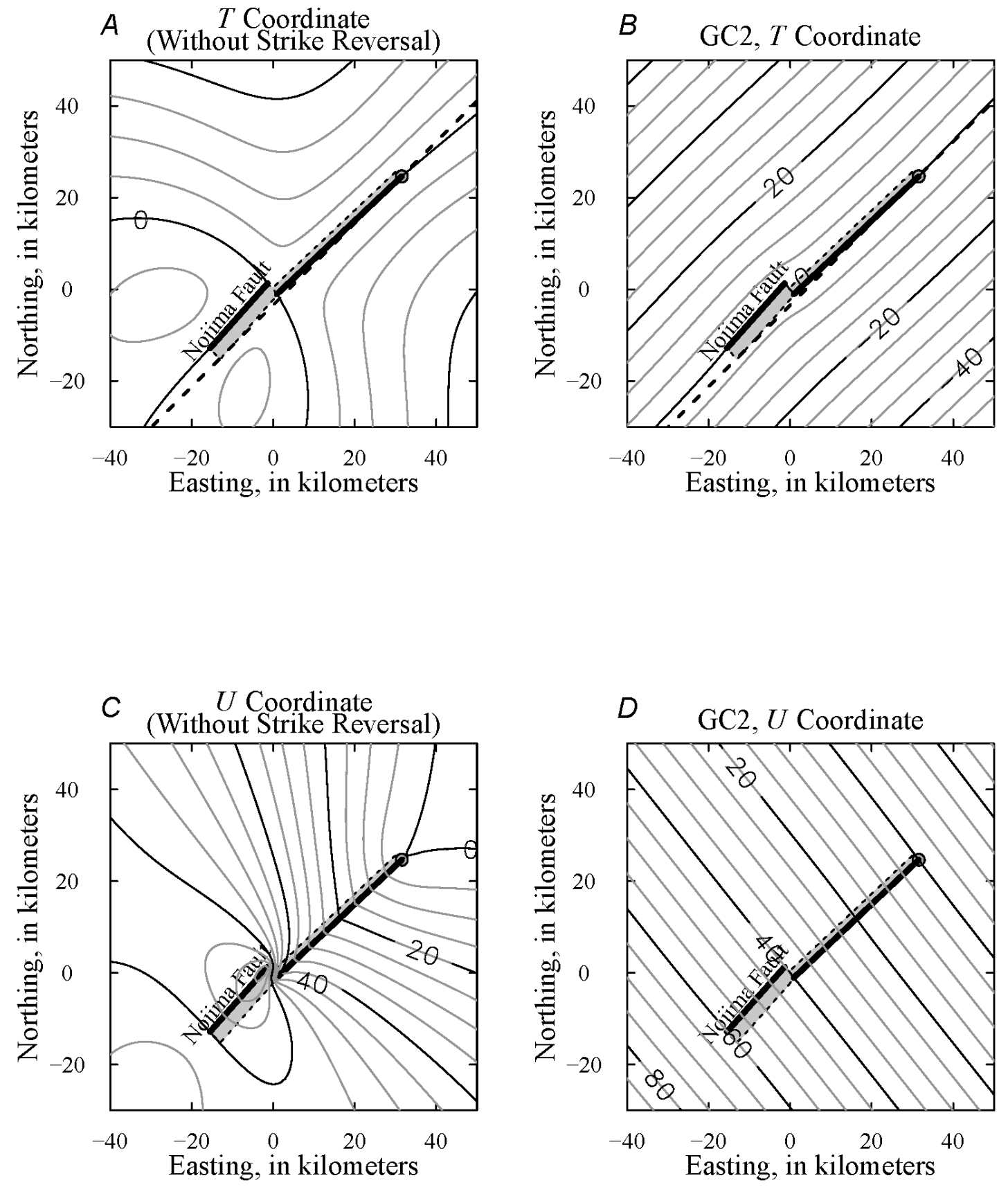

Figure 7. Contour maps of generalized coordinates for sites located around the rupture of the $1995 \mathrm{Kobe}$, Japan, earthquake. $A, T$ coordinate, strike of the Nojima fault not reversed; $B, T$ coordinate of $G C 2$. $C, U$ coordinate, strike of the Nojima Fault not reversed; $D, U$ coordinate of GC2. Thick solid lines, rupture traces; gray solid point, common origin of $U$; thick dashed line, the line passing through the common origin and whose direction vector is the nominal strike $\widehat{\boldsymbol{b}}$. 

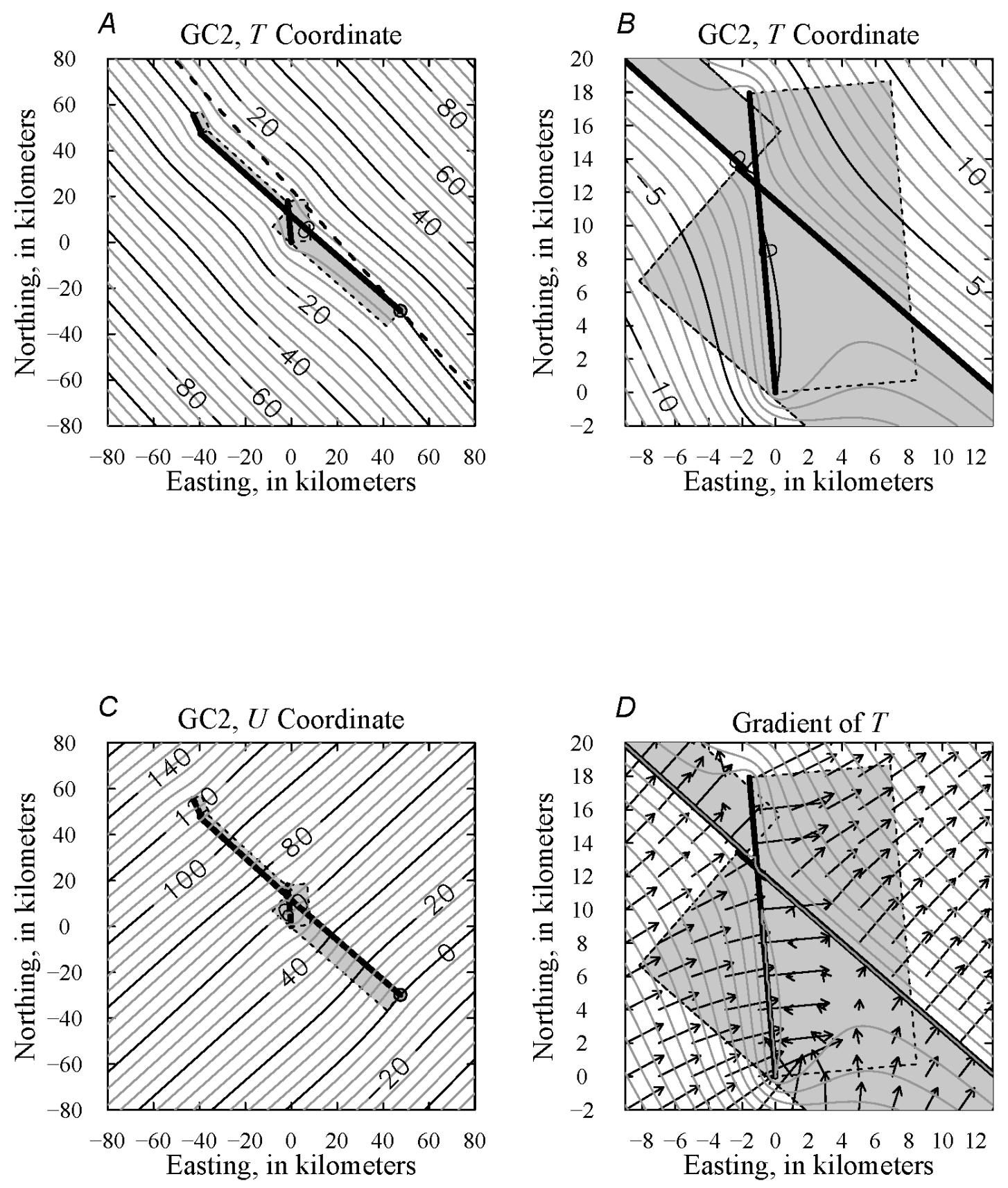

Figure 8. Contour and gradient maps of generalized coordinates for sites located around the rupture of the $2010 \mathrm{EI}$ Mayor Cucapah, Mexico, earthquake. $A, T$ of GC2; B, T of GC2 focused on the central part of rupture; $C, U$ of GC2; $D$, Gradient of $T$ focused on to the central part of rupture. Thick solid lines, rupture traces; gray solid point, common origin of $U$; shaded areas; buried parts of the rupture; thick dashed line, the line passing through the common origin and whose direction vector is the nominal strike $\widehat{\boldsymbol{b}}$. 

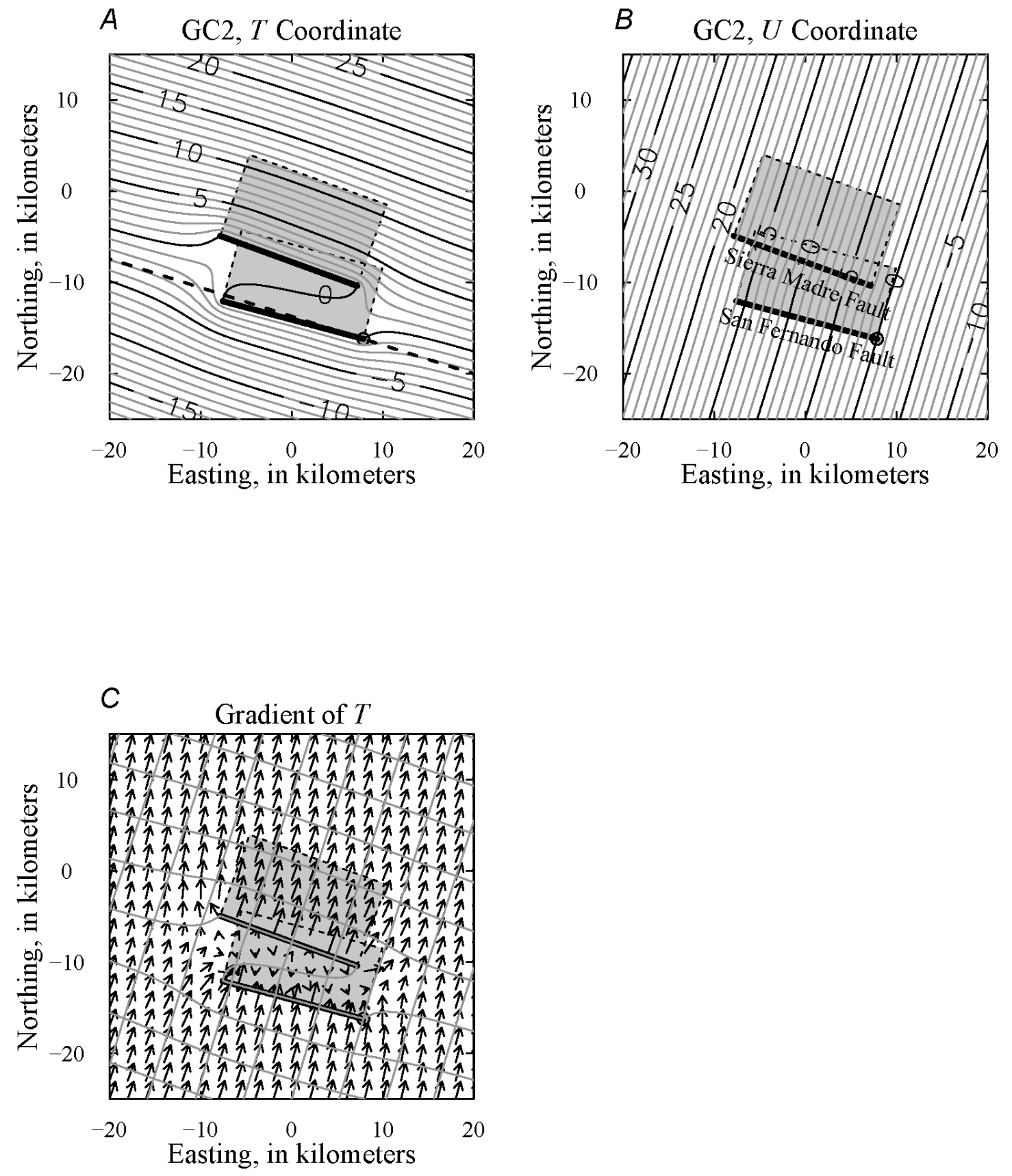

Figure 9. Contour and gradient maps of generalized coordinates for sites located around the rupture of the 1971 San Fernando, California, earthquake. $A, T$ of GC2; $B, U$ of GC2; $C$, Gradient of $T$. Thick solid lines, rupture traces; gray solid point, common origin of $U$; shaded areas, buried parts of the rupture; thick dashed line, the line passing through the common origin and whose direction vector is the nominal strike $\widehat{\boldsymbol{b}}$. 
This page left intentionally blank 
Publishing support provided by the U.S. Geological Survey Science Publishing Network, Menlo Park and Tacoma Publishing Service Centers

For more information concerning the research in this report, contact the Earthquake Science Center - Menlo Park

U.S. Geological Survey

345 Middlefield Road, MS 977

Menlo Park, CA 94025

http://earthquake.usgs.gov/ 
